\title{
POLA PENGGUNAAN RUANG DAN WAKTU RUSA SAMBAR (Rusa unicolor) DI RAGUNAN
}

\section{PATTERN OF USE OF SPACE AND TIME RUSHED (Unicolor deer) IN RAGUNA}

\author{
Julaili Irni \\ Fakultas Agro Teknologi, Universitas Prima Indonesia, Indonesia \\ Diterima: 15 Maret 2021; Disetujui: 29 Maret 2021; Dipublish: 31 Maret 2021
}

*Coresponding Email: julianiirni@yahoo.com

\begin{abstract}
Abstrak
Aktivitas harian merupakan semua aktivitas yang dilakukan oleh satwa sehari-hari mulai dari pagi hari keluar dari sarang hingga sore hari dan kembali lagi ke sarang. Penelitian ini bertujuan untuk mengetahui pola aktivitas dari rusa sambar (Rusa unicolor). Pengamatan ini dilakukan dikebun binatang Ragunan yang dilakukan 3 tahap yaitu pagi, siang dan sore hari. Penelitian ini mengamati pola penggunaan waktu dan penggunaan ruang yang diamati pada rusa sambar dengan kategori 5 kelas umur yaitu jantan dewasa, betina dewasa, jantan muda betina muda dan anakan. Hasil penelitian yang diperoleh dari aktivitas rusa sambar pada pagi hari yaitu alokasi waktu untuk aktivitas harian pagi hari pada tiap kelas umur berbeda, alokasi waktu aktivitas makan, berpindah, dan istirahat pada periode siang hari untuk setiap kelas umur individu rusa adalah berbeda serta alokasi waktu untuk aktivitas harian sore hari pada tiap kelas umur berbeda. Sebagian besar rusa sambar di Ragunan lebih menyukai berada di padang rumput bawah tegakan untuk beraktivitas. Alokasi waktu (time budget) rusa sambar pada kelas umur dan jenis kelamin dipengaruhi oleh waktu aktivitas (pagi-siang-sore).
\end{abstract}

Kata Kunci: Pola; Aktivitas; Satwa; Rusa Sambar; Ragunan.

\begin{abstract}
Daily activities are all activities carried out by animals daily starting from the morning out of the nest until late in the evening and back again to the nest. This study aims to determine the activity pattern of sambar deer (Rusa unicolor). This observation was carried out at the Ragunan zoo which was carried out in 3 stages, namely morning, afternoon and evening. This study observed the patterns of time use and space use observed in sambar deer with 5 age class categories, namely adult males, adult females, young males and young females. The results of the research obtained from the activity of the sambar deer in the morning, namely the allocation of time for daily activities in the morning for each different age class, the allocation of time for feeding, moving, and resting activities during the daytime period for each individual age class of the deer is different and the time allocation for daily activities in the afternoon for each age class is different. Most of the sambar deer in Ragunan prefer to be in the grass below the stands for their activities. Time allocation (time budget) for sambar deer in age class and sex is influenced by the time of activity (morning-afternoon-evening).
\end{abstract}

Keywords: Patterns, Activities; Animals; Sambar Deer; Ragunan.

How to Cite: Irni, J. (2020). Pola Penggunaan Ruang Dan Waktu Rusa Sambar (Rusa Unicolor) di Ragunan. Journal of Natural Sciences. Vol 1 (3): 129-135. 



\section{PENDAHULUAN}

Pola penggunaan waktu adalah pengalokasian waktu untuk setiap aktivitas harian yang dilakukan oleh satwa. Pola penggunaan waktu yang dilakukan oleh satwa liar terbagi atas 2 bagian yaitu aktivitas harian dan alokasi waktu. Aktivitas harian merupakan semua aktivitas yang dilakukan oleh satwa sehari-hari mulai dari pagi hari keluar dari sarang hingga sore hari dan kembali lagi ke sarang (Bunga dkk, 2018). Aktivitas harian bergantung pada lingkungan disekitar satwa sebagai sumber pakan, tempat bermain, dan beristirahat. Pola penggunaan waktu ini dianalisis pada saat melakukan pengamatan terhadap aktivitas harian suatu jenis satwa untuk setiap kelas umur (Rahayu, 2006).

Pola penggunaan waktu pada kelompok taksa burung dibagi menjadi tiga tipe perilaku yaitu: berjaga terhadap predator, makan, dan bersaing untuk memperoleh makanan; dengan kodisi bahwa: Proporsi penggunaan waktu untuk berjaga dari musuh akan menurun seiring dengan meningkatnya ukuran kelompok. Dasar asumsi ini adalah bahwa tingkat kewaspadaan dapat dijaga dengan sedikit berjaga ketika ukuran kelompok meningkat. Ketika ukuran kelompok meningkat dan perjumpaan antar burung akan menjadi lebih sering, proporsi waktu untuk agresi menjadi lebih banyak. Waktu untuk makan menjadi sangat maksimum ketika ukuran kelompok sedang (Sawitri \& Takandjandji, 2010).

Berdasarkan uraian diatas, perlu dilakukan analisis penggunaan waktu pada satwa, sebab penggunaan waktu pada setiap jenis kelamin dan kelas umur tersebut berbeda-beda pada berbagai kelas individu. Dengan kata lain lama satwa beraktivitas cenderung bervariasi untuk setiap kelas individu baik jantan dewasa, betina dewasa, remaja dan anak dari waktu ke waktu. 


\section{METODE PENELITIAN}

Pengamatan ini dilakukan pada bulan April 2015 dikebun binatan Ragunan yang dilakukan 3 tahap yaitu pagi hari mulai pukul (09.00-11.00), (11.00-13.00) untuk siang, (13.00-15.00) untuk sore hari. Dalam pengamatan ini ada beberapa alat dan bahan yang digunakan yaitu tallysheet, kamera, stopwatch, alat tulis serta binokuler dan rusa sambar (Rusa unicolor) dengan kategori 5 kelas umur yaitu jantan dewasa, betina dewasa, jantan muda betina muda dan anakan.

Penggunaan waktu

Untuk penggunaan waktu pengamatan ini menggunakan metode focal animal sampling yang bertujuan untuk mengetahui perilaku satwa dalam melakukan aktivitas, beberapa hal yang perlu diamati adalah :

1. Waktu rusa saat melakukan aktivitas : Kelas individu yang diklasifikasikan berdasarkan jenis kelamin dan kelas umur, yaitu: Jantan dewasa,Betina dewasa,Jantan muda,Betina mudaAnak-anak

2. Jenis perilaku atau Aktivitas yang diamati meliputi : Makan (feeding), meliputi merenggut makanan dan prosesnya, dilakukan di savana

3. Berpindah (moving), merupakan pergerakan satwa yang dilakukan dari satu tempat ketempat lain untuk mencari makanan atau menggerakkan kaki menjauhi tempat semula. Khusus untuk anak aktivitas berpindah juga meliputi aktivitas bermain seperti berlari-lari, melompat-lompat dan bercanda.

4. Istirahat (resting), aktifitas istirahat merupakan bagian dari perilaku mencari tempat berlindung (shelter seeking), meliputi aktivitas berdiri di bawah pohon. Duduk atau rebahan di tempat teduh disertai dengan aktifitas memamah biak, membersihkan diri (grooming) dengan cara menjilat-jilati badan.

\section{Penggunaan ruang}

Penggunaan ruang dilakukan dengan menganalisis menggunakan metode Chi-square untuk mengetahui adanya perbedaan penggunaan ruang dengan aktivitas yang dilakukan

\footnotetext{
https://journal.mahesacenter.org/index.php/jonas

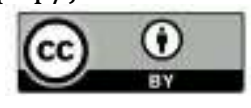

… mrc@mahesacenter.org

130

This work is licensed under a Creative Commons Attribution 4.0 
Vol.1, No.3, November 2020: 129-135.

dengan menguji hipotesis (Ho) bahwa penggunaan ruang oleh satwa dalam beraktivitas adalah sama, seangkan hipotesis alternatif (H1) bahwa penggunaan ruang oleh rusa dalam beraktifitas berbeda.

$$
X_{\text {hitung }}^{2}=\frac{(O i-E i)^{2}}{E i}
$$

Keterangan :

$\mathrm{Ei} \quad=$ Nilai harapan

$\mathrm{Oi} \quad=$ Jumlah petak yang terdapat jumlah individu sebanyak Xi

Kriteria uji tolah H0 jika $X_{\text {hitung }}^{2}>X_{(0,05, d b)}^{2}$ derajat bebas $=(\mathrm{b}-1)(\mathrm{K}-1)$ dengan $\mathrm{b}$ adalah jumlah baris dan $\mathrm{k}$ adalah jumlah kolom.

Hipotesis :

Ho : Penggunaan waktu oleh setiap kelas individu adalah sama

H1 : Penggunaan waktu oleh setiap kelas individu adalah berbeda

$\chi^{2}$ hitung $<\chi^{2}$ tabel, Ho diterima

$\chi^{2}$ hitung $>\chi^{2}$ tabel, Ho ditolak

\section{HASIL DAN PEMBAHASAN}

Dari hasil pengamatan pola penggunaan waktu ini dapat diperoleh beberapa data seperti yang ditampilkan pada tabel dibawah ini:

Table 1. Aktivitas harian rusa sambar (Rusa unicolor) pada pagi hari

\begin{tabular}{|c|c|c|c|c|}
\hline \multirow{2}{*}{ Kelas Umur } & \multicolumn{3}{|c|}{ Aktivitas Harian (menit) } & \multirow{2}{*}{ Tota } \\
\hline & Makan & Berpindah & Istirahat & \\
\hline Jantan Dewasa & 53 & 12 & 55 & 120 \\
\hline Jantan Muda & 47 & 15 & 58 & 120 \\
\hline Betina Dewasa & 39 & 12 & 69 & 120 \\
\hline Betina Muda & 61 & 3 & 56 & 120 \\
\hline Anak & 28 & 8 & 84 & 120 \\
\hline Total & 228 & 50 & 322 & 600 \\
\hline
\end{tabular}

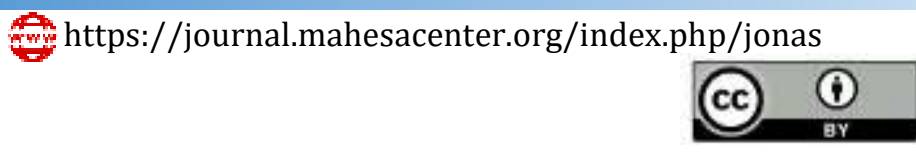

This work is licensed under a Creative Commons Attribution 4.0 
Tabel 2. Proporsi aktivitas harian rusa

\begin{tabular}{|c|c|c|c|c|}
\hline \multirow[b]{2}{*}{ Kelas Umur } & \multicolumn{3}{|c|}{ Aktivitas Harian (\%) } & \multirow[b]{2}{*}{ Total } \\
\hline & Makan & Berpindah & Istirahat & \\
\hline Jantan Dewasa & 44,17 & 10,00 & 45,83 & 100 \\
\hline Jantan Muda & 39,17 & 12,50 & 48,33 & 100 \\
\hline Betina Dewasa & 32,50 & 10,00 & 57,50 & 100 \\
\hline Betina Muda & 50,83 & 2,50 & 46,67 & 100 \\
\hline Anak & 23,33 & 6,67 & 70,00 & 100 \\
\hline
\end{tabular}

\section{Aktivitas harian rusa sambar (Rusa unicolor) pada siang hari}

Tabel 3. Aktifitas harian rusa sambar (Rusa unicolor) pada siang hari di Ragunan.

\begin{tabular}{lcccc}
\hline \multicolumn{1}{c}{ Kelas umur } & Makan & $\begin{array}{c}\text { Aktivitas harian } \\
\text { Berpindah }\end{array}$ & Istirahat & Total \\
\hline Jantan dewasa & 55 & 15 & 50 & $\mathbf{1 2 0}$ \\
Jantan muda & 70 & 11 & 39 & $\mathbf{1 2 0}$ \\
Betina dewasa & 60 & 30 & 30 & $\mathbf{1 2 0}$ \\
Betina muda & 56 & 2 & 62 & $\mathbf{1 2 0}$ \\
Anakan & 34 & 12 & 74 & $\mathbf{1 2 0}$ \\
\hline Total & $\mathbf{2 7 5}$ & $\mathbf{7 0}$ & $\mathbf{2 5 5}$ & $\mathbf{6 0 0}$ \\
\hline
\end{tabular}

Tabel 4. Proporsi aktivitas harian rusa pada siang hari

\begin{tabular}{lcccc}
\hline Kelas Umur & Makan & $\begin{array}{c}\text { Aktivitas Harian } \\
\text { Berpindah }\end{array}$ & Istirahat & Total \\
\hline jantan dewasa & 45,83 & $\mathbf{1 2 , 5 0}$ & 41,67 & 100, oo \\
jantan muda & 58,33 & 9,17 & 32,50 & 100,00 \\
betina dewasa & 50,00 & $\mathbf{2 5 , 0 0}$ & $\mathbf{2 5 , 0 0}$ & 100, oo \\
betina muda & 46,67 & 1,67 & 51,67 & 100, oo \\
anakan & $\mathbf{2 8 , 3 3}$ & 10,00 & 61,67 & 100, oo \\
\hline total & $\mathbf{2 2 9 , 1 7}$ & $\mathbf{5 8 , 3 3}$ & $\mathbf{2 1 2 , 5 0}$ & $\mathbf{5 0 0 , 0 0}$ \\
\hline
\end{tabular}

Aktivitas harian rusa sambar (Rusa unicolor) pada siang hari

Tabel 5. Aktivitas sore hari

\begin{tabular}{|c|c|c|c|c|c|}
\hline \multirow{2}{*}{ Kelas Umur } & \multicolumn{3}{|c|}{ Aktivitas Harian } & \multirow{2}{*}{ Total } & \\
\hline & Makan & Berpindah & Istirahat & & \\
\hline Jantan Dewasa & 71 & 12 & 37 & 120 & \\
\hline Jantan Muda & 96 & 11 & 13 & 120 & \\
\hline Betina Dewasa & 107 & 3 & 10 & 120 & \\
\hline Betina Muda & 106 & 3 & 11 & 120 & \\
\hline Anak & 32 & 17 & 71 & 120 & \\
\hline Total & 412 & 46 & 142 & 600 & \\
\hline Whs://jour & 8 & jonas & nrc@m & org & 132 \\
\hline
\end{tabular}

This work is licensed under a Creative Commons Attribution 4.0 
Tabel 6. Proporsi aktivitas harian rusa sambar pada siang hari

\begin{tabular}{lcccc}
\hline \multicolumn{1}{c}{ Kelas Umur } & Makan & $\begin{array}{c}\text { Aktivitas Harian } \\
\text { Berpindah }\end{array}$ & Istirahat & Total \\
\hline Jantan Dewasa & 59,17 & 10,00 & 30,83 & $\mathbf{1 0 0}$ \\
Jantan Muda & 80, oo & 9,17 & 10,83 & $\mathbf{1 0 0}$ \\
Betina Dewasa & 89,17 & 2,50 & 8,33 & $\mathbf{1 0 0}$ \\
Betina Muda & 88,33 & 2,50 & 9,17 & $\mathbf{1 0 0}$ \\
Anak & 26,67 & 14,17 & 59,17 & $\mathbf{1 0 0}$ \\
\hline
\end{tabular}

Data penggunaan ruang dihitung berdasarkan frekuensi dan berdasarkan hasil uji hipotesis. Dimana diketahui bahwa tidak ada perbedaan penggunaan ruang (kuadran) oleh semua kelas umur rusa daam melakukan aktifitasnya.

Tabel 7. Hasil pengujian dan frekensi penggunaan ruang oleh rusa

\begin{tabular}{llccc}
\hline No. & Kelas umur dan jenis kelamin & X2 hitung & X2 tabel & Derajat bebas \\
\hline 1 & Anak & 4,053 & 15,548 & 6 \\
2 & Jantan dewasa & 5,215 & 15,548 & 6 \\
3 & Betina dewasa & 11,115 & 15,548 & 6 \\
4 & Jantan muda & 6,843 & 15,548 & 6 \\
5 & Betina muda & 3,763 & 15,548 & 6 \\
\hline
\end{tabular}


Dari hasil tabel diatas dapat ditunukkan bahwa lintasan sebagai penggunaan ruang terbesar adalah rusa jantan dewasa, selanjutnya betina dewasa dan yang paling kecil adalah anakan yang lebih banyak beristirahat pada naungan dan berada dibawah lindungan induknya. Berdasarkan analisis chi-square diperoleh ternyata panjang lintasan tidak berbeda menurut kelas umur dan jenis kelamin. Ini berarti, jelas ada perbedaan panjang lintasan pergerakan rusa sambar ternyata tidak dipengaruhi oleh kelas umur dan jenis kelamin. Sedangkan berdasarkan hasil uji statistik, fenomena pada alokasi waktu (time budget) aktivitas per jenis kelamin dan kelas umur menunjukkan alokasi waktu (time budget) rusa pada kelas umur dan jenis kelamin dipengaruhi oleh waktu aktivitas (pagi-siang-sore). Rusa sambar (Rusa unicolor) dikebun binatang Ragunan berdasarkan hasil pengamatan tidak memiliki banyak variasi aktivitas ialah makan, berpindah, memamah biak, dan istirahat. Jarang sekali ditemukan rusa totol berinteraksi sosial termasuk berperilaku membuang kotoran, minum, dan kawin. Ada korelasi yang cukup kuat antara tipe habitat (vegetasi rimbun) dengan variasi aktivitas, lama aktivitas dan waktu aktivitas. Vithanage dkk (2019) melaporkan aktivitas istirahat dan memamah biak rusa sambar di Sri Lanka biasa dilakukan mulai pukul 09.00 pagi hingga sore hari pukul 16.00. Dewi \& Wulandari (2011) juga melaporkan rusa sambar cenderung menghentikan aktivitas lainnya kecuali istirahat pada siang hari.

Di dalam pengamatan ini, memamah biak tetap dipisahkan dari aktivitas makan dan berpindah. Hal ini senada dengan pernyataan Garsetiasih dan Sutrisno (1997), sebagian besar rusa melakukan aktivitas makan bersamaan dengan kegiatan berpindahnya (lokomosi). Sementara rusa anakan cenderung mengikuti induknya dalam bergerak sehingga jelas telihat bahwa rusa dewasa dan rusa anakan memiliki panjang lintasan dan luas wilayah jelajah lebih panjang dan luas. Hal ini senada dengan laporan Takandjandji (1993) bahwa pergerakan anak dipengaruhi oleh pergerakan induknya atau rusa dewasa. 


\section{SIMPULAN}

Sebagian besar rusa sambar (Rusa unicolor) di Ragunan.lebih menyukai berada di padang rumput bawah tegakan untuk beraktivitas. Alokasi waktu (time budget) rusa sambar pada kelas umur dan jenis kelamin dipengaruhi oleh waktu aktivitas (pagi-siangsore).

\section{DAFTAR PUSTAKA}

Bunga, R., Kawatu, M. M., Wungow, R. S. H., \& Rompas, J. J. (2018). AKTIVITAS HARIAN RUSA TIMOR (Cervus timorensis) DI TAMAN MARGA SATWA TANDURUSA AERTEMBAGA, BITUNG-SULAWESI UTARA. Zootec, 38(2), 345-356.

Dewi, B. S., \& Wulandari, E. (2011). Studi perilaku harian rusa sambar (Cervus unicolor) di taman wisata alam Bumi Kedaton. Jurnal Sains MIPA, 17(2), 75-78.

Rahayu, D. (2006). Analisis Pola Penggunaan Waktu Bos javanicus d'alton Di Padang Pengembalaan Sadengan Taman Nasional Alas Purwo, Jawa Timur. Fak. Kehutanan IPB. Bogor.

Sawitri, R., \& Takandjandji, M. (2010). Pengelolaan dan perilaku burung elang di Pusat Penyelamatan Satwa Cikananga, Sukabumi. Jurnal Penelitian Hutan dan Konservasi Alam, 7(3), 257-270.

Vithanage, D. A. J., Bandara, D. M. N. S., Wijekoon, W. M. G. W. P. M. B., \& Nishantha, P. G. S. (2019). First and true albinism records of albino Sambar deers (Rusa unicolor unicolor)(Gona, Gona Muwa) in Sri Lanka. WILDLANKA Journal of the Department of Widllife Conservation of Sri Lanka, 7(2). 